Supporting Information

\title{
High Enhancement in Proton Conductivity by Incorporating Sulfonic Acids into a Zirconium-based Metal-Organic Framework via "Click" Reaction
}

\section{Xin-Nan Zou, ${ }^{\dagger}$ Deshan Zhang, ${ }^{\dagger}$ Yulong Xie ${ }^{\dagger}$ Tian-Xiang Luan, ${ }^{\dagger}$ Wanchao Li $^{\S}{ }^{\S}$ Lei Li, ${ }^{\dagger}$} Pei-Zhou Li*i,

${ }^{\dagger}$ School of Chemistry and Chemical Engineering, Shandong University, No.27 Shanda South Road, Ji'nan 250100, Shandong Province, People's Republic of China

${ }^{\ddagger}$ Science Center for Material Creation and Energy Conversion, Institute of Frontier and Interdisciplinary Science, Shandong University, Qingdao 266237, Shandong Province, People's Republic of China

${ }^{\S}$ No.1 Institute of Geology and Mineral Resources of Shandong Province, No. 521 Jingde Road, Ji'nan 250100, Shandong Province, People's Republic of China

* Corresponding Authors. E-mail: pzli@sdu.edu.cn 


\section{General information}

All starting materials are commercially available and were used as received unless specifically mentioned.

Powder X-ray diffraction (PXRD) patterns were recorded on a SmartLab $9 \mathrm{~kW}$ X-Ray diffractometer using $\mathrm{Cu} \mathrm{Ka}$ radiation $(\lambda=1.5418 \AA)$ over $2 \theta$ range of $2.0^{\circ}-50^{\circ}$ at room temperature. Fourier transform infrared (FT-IR) measurements were performed on an Avatar 370 FT-IR spectrometer. Thermogravimetric analyses (TGA) were carried out on a TGA-Q500 thermoanalyzer with a heating rate of $20{ }^{\circ} \mathrm{C} \min ^{-1}$ under $\mathrm{N}_{2}$ flow $(50 \mathrm{~mL} / \mathrm{min})$ from room temperature to $600{ }^{\circ} \mathrm{C}$. Surface area distribution were analyzed by $\mathrm{N}_{2}$ adsorption and desorption using a Kubo-X1000 at $77 \mathrm{~K}$ after pretreatment by degassing the sample under vacuum at the temperature of $120^{\circ} \mathrm{C}$ for $6 \mathrm{~h}$.

\section{Experimental section}

Synthesis of UiO-66- $\mathbf{N H}_{2}$. The 2-aminoterephthalic acid linker, $\mathrm{H}_{2} \mathrm{BDC}-\mathrm{NH}_{2}(14.5 \mathrm{mg}, 0.08$ $\mathrm{mmol})$, and inorganic metal precursor, $\mathrm{ZrCl}_{4}(9.3 \mathrm{mg}, 0.04 \mathrm{~mol})$, were dissolved in the mixture solution of N,N'-dimethylformamide (DMF, $6 \mathrm{~mL}$ ) and $\mathrm{HCl}$ (4 drops). Then, the mixture solution was placed in a tightly capped $20 \mathrm{~mL}$ vial and was heated in an oven at $85{ }^{\circ} \mathrm{C}$ for 1 day. After cooling the sample down to room temperature, yellow powder of UiO-66- $\mathrm{NH}_{2}$ was successfully obtained. The collected powder was washed by ethanol and acetone for 3 times and dried naturally at room temperature to yield activated $\mathrm{UiO}-66-\mathrm{NH}_{2}$.

Synthesis of UiO-66- $\mathbf{N}_{3}$. UiO-66- $\mathrm{NH}_{2}(400 \mathrm{mg})$ was suspended in a mixture of $\mathrm{MeOH}(50$ $\mathrm{mL})$ and $\mathrm{HCl}(1 \mathrm{M}, 50 \mathrm{~mL})$ at $0{ }^{\circ} \mathrm{C} .{ }^{\mathrm{S} 1-\mathrm{S} 2}$ Subsequently, a water solution of $\mathrm{NaNO}_{2}(0.32 \mathrm{~g}, 4.2$ mmol, $5 \mathrm{~mL} \mathrm{H}_{2} \mathrm{O}$ ) was added dropwise into the above mixture, and the resulting suspension was stirred at $0{ }^{\circ} \mathrm{C}$ for $2 \mathrm{~h}$. Then, a solution of $\mathrm{NaN}_{3}\left(0.32 \mathrm{~g}, 4.2 \mathrm{mmol}, 5 \mathrm{~mL} \mathrm{H}_{2} \mathrm{O}\right)$ was added dropwise into the suspension at $0{ }^{\circ} \mathrm{C}$ with stirring for $2 \mathrm{~h}$ (Noted: $\mathrm{NaN}_{3}$ is an explosive chemical. When taking it out from the bottle, please use plastic spoon instead of metal spoon and do not hit or squeeze the sample). The yellow powder was centrifuged and washed by water and ethanol (15 mL each) for 3 times, and then evacuated in vacuum under $60{ }^{\circ} \mathrm{C}$ for $6 \mathrm{~h}$. 
Synthesis of UiO-66-SO $\mathrm{S}_{3} \mathrm{H}$. Typically, propynesulfonic acid sodium salt $(0.28 \mathrm{~g})$ was added into a DMF suspension $(50 \mathrm{~mL})$ of $\mathrm{UiO}-66-\mathrm{N}_{3}(100 \mathrm{mg})$ that was pre-degassed by $\mathrm{N}_{2}$ for 30 min. Then, $\mathrm{CuBr}(14 \mathrm{mg}, 0.1 \mathrm{mmol})$ was added into the above suspension, which was stirred at $60{ }^{\circ} \mathrm{C}$ under $\mathrm{N}_{2}$ for 2 days. After cooling down to room temperature and keeping in atmosphere overnight, the green raw product was centrifuged and washed by water and ethanol (15 mL each) for 3 times, and then evacuated in vacuum under $60{ }^{\circ} \mathrm{C}$ for $6 \mathrm{~h}$. After acidification by washing the samples with $0.01 \mathrm{M} \mathrm{H}_{2} \mathrm{SO}_{4}$ repeatedly for more than 3 days, thoroughly washing by water was carried out until the eluent reaching $\mathrm{pH}=7$ and no precipitation being generated when titrated with barium chloride dilute solution.

Impedance analyses. $\mathrm{AC}$ impedance data were obtained using a pellet (6 $\mathrm{mm}$ in diameter) pressed at $6,000 \mathrm{~kg}$ for a couple of minutes. The thickness of the pellet was about $2 \mathrm{~mm}$ (exact values were obtained by the measurements of Vernier caliper). The pellet was placed in a home-made sample holder composed of $\mathrm{Cu}$-pressed electrodes and the sample holder was put in a temperature and humidity controlled chamber. Data points were obtained after the sample being equilibrated over $30 \mathrm{~min}$. 


\section{Figures}
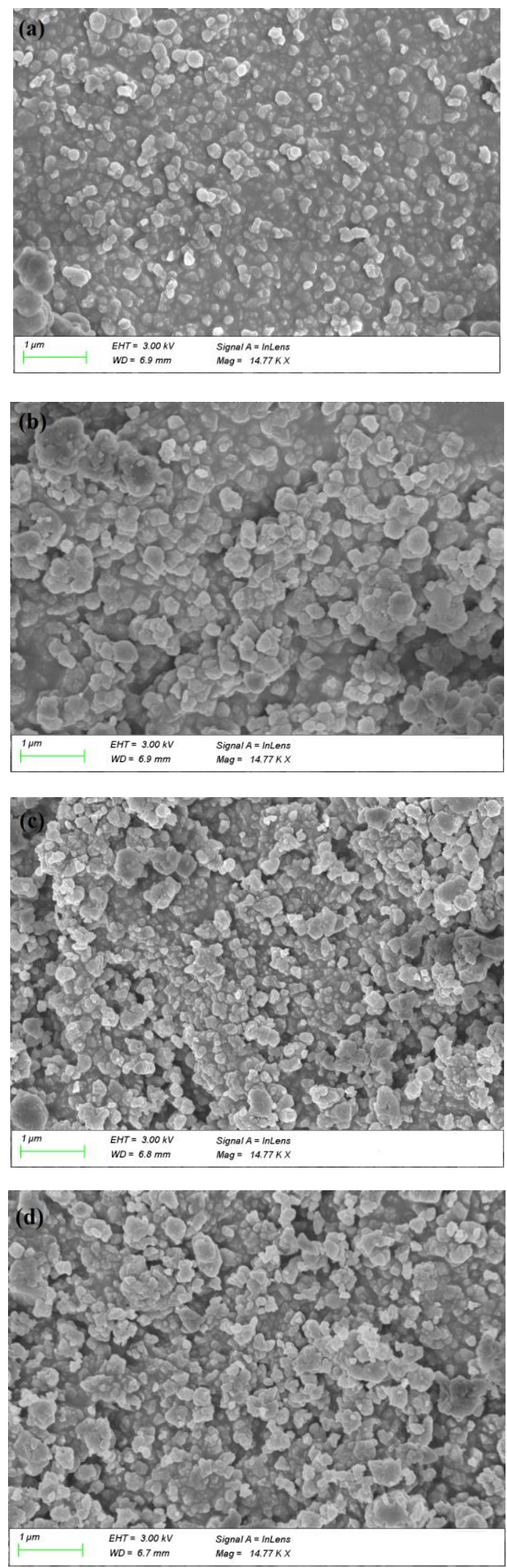

Figure S1. SEM images of (a) UiO-66; (b) UiO-66- $\mathrm{NH}_{2}$; (c) $\mathrm{UiO}^{-66-\mathrm{N}_{3}}$ and (d) $\mathrm{UiO}-66-\mathrm{SO}_{3} \mathrm{H}$. 


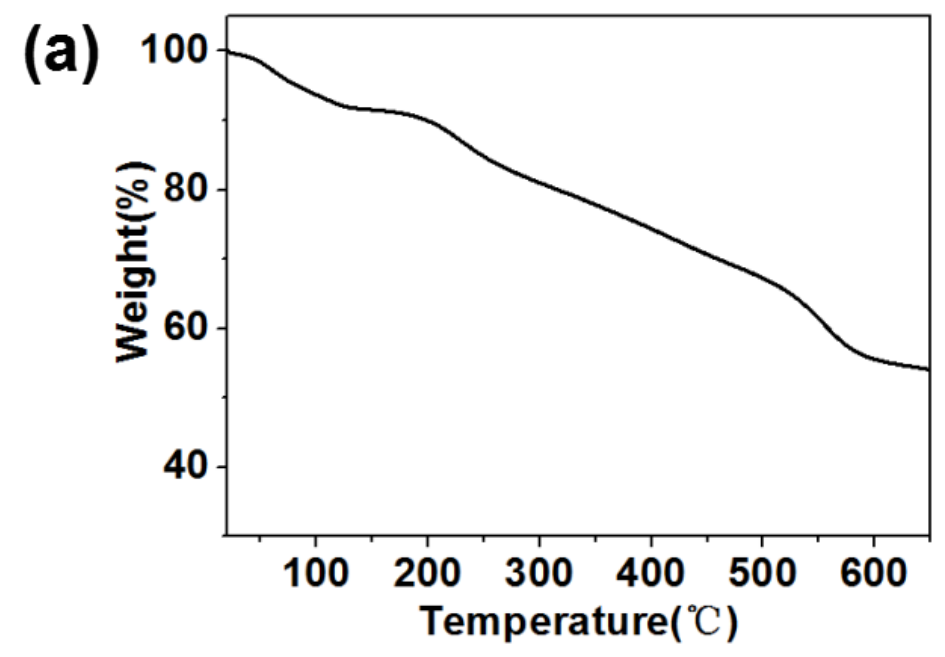

(b)
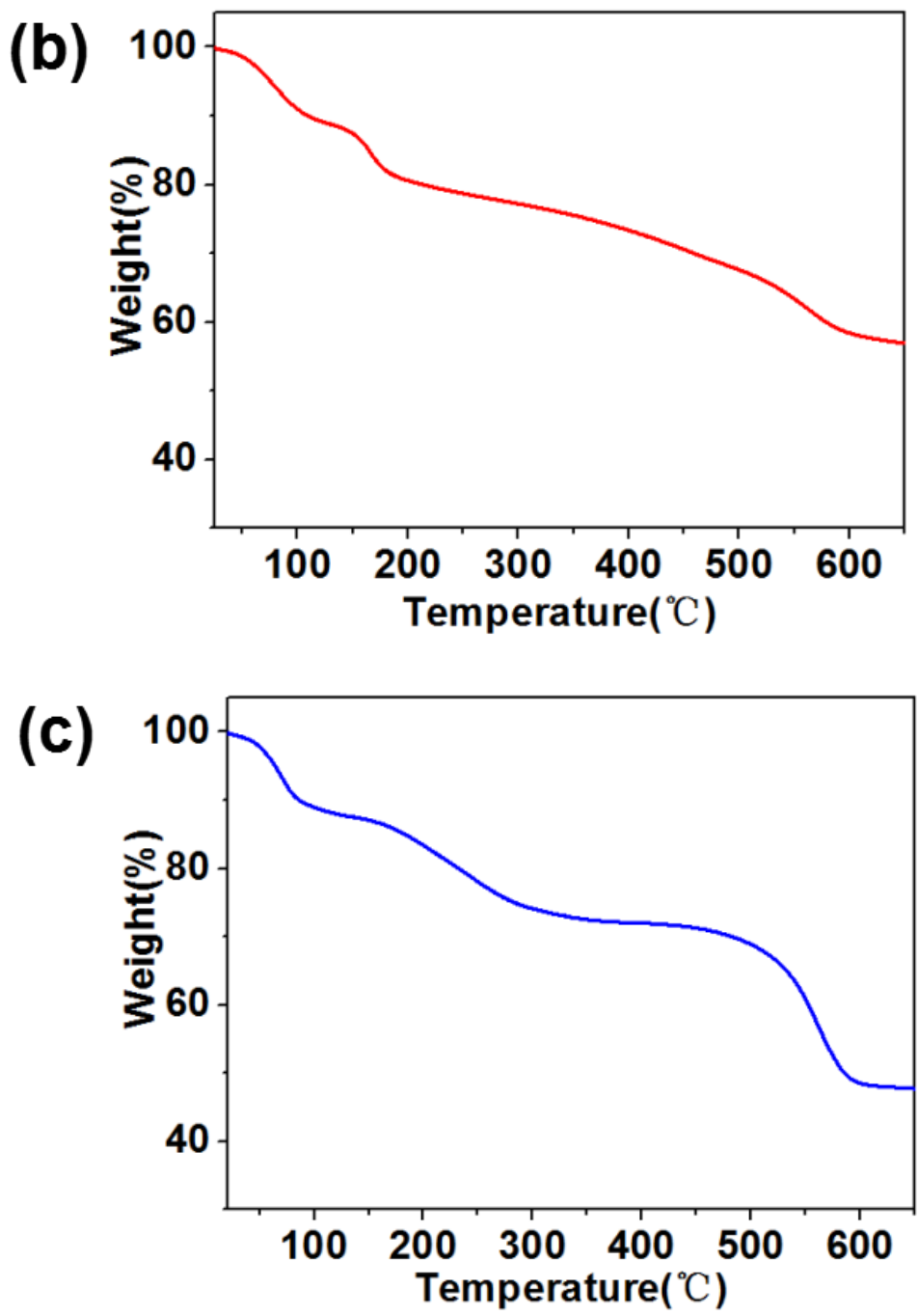

Figure S2. TG analyses of (a) UiO-66- $\mathrm{NH}_{2}$; (b) $\mathrm{UiO}-66-\mathrm{N}_{3}$; (c) $\mathrm{UiO}-66-\mathrm{SO}_{3} \mathrm{H}$. 


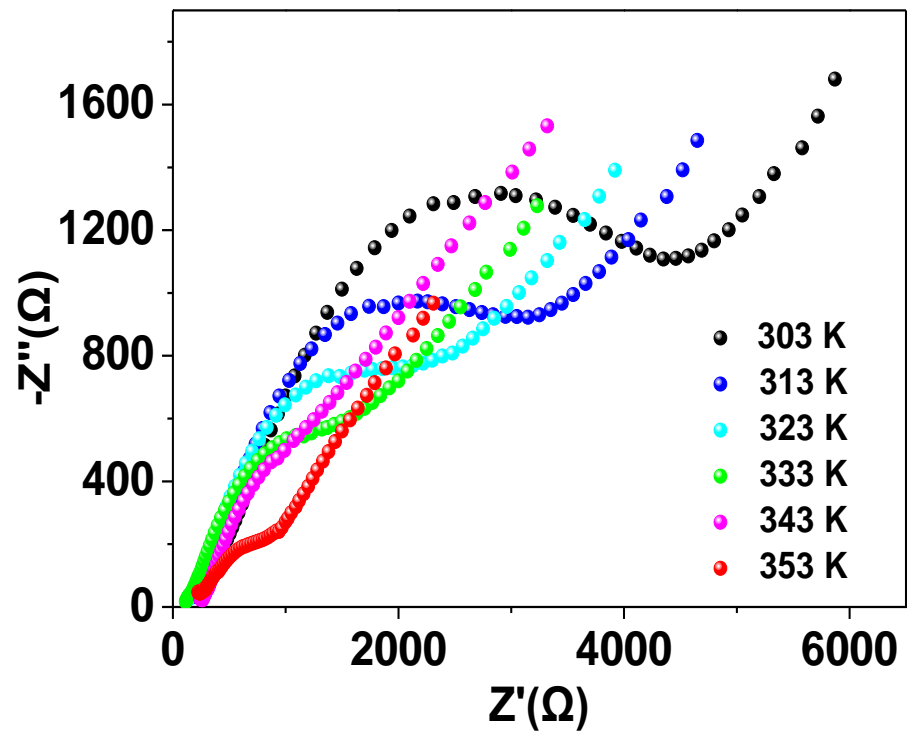

Figure S3. Nyquist plots for $\mathrm{UiO}-66-\mathrm{SO}_{3} \mathrm{H}$ at $75 \% \mathrm{RH}$.

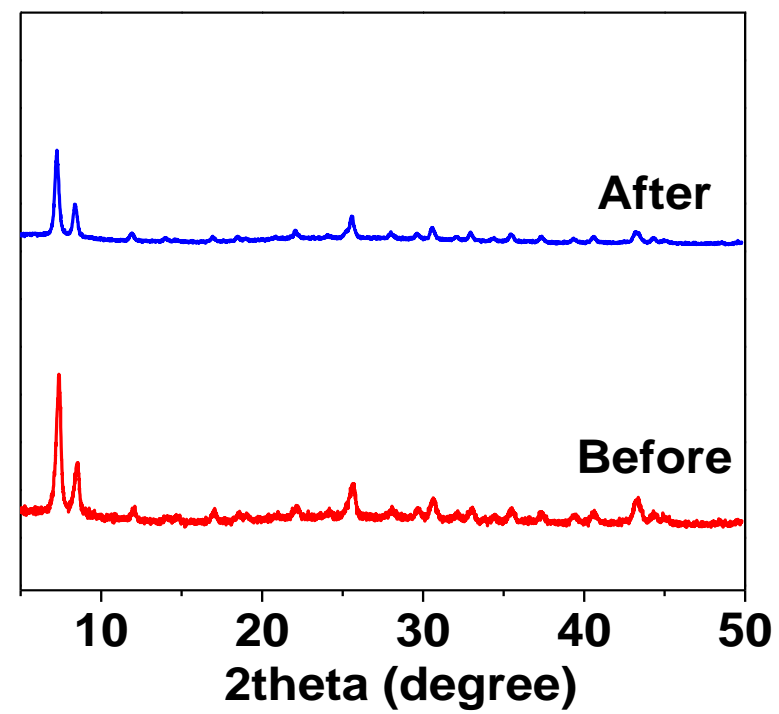

Figure S4. PXRD data for the samples of UiO-66- $\mathrm{SO}_{3} \mathrm{H}$ before (red) and after continuous test for more than 20 hours (blue). 


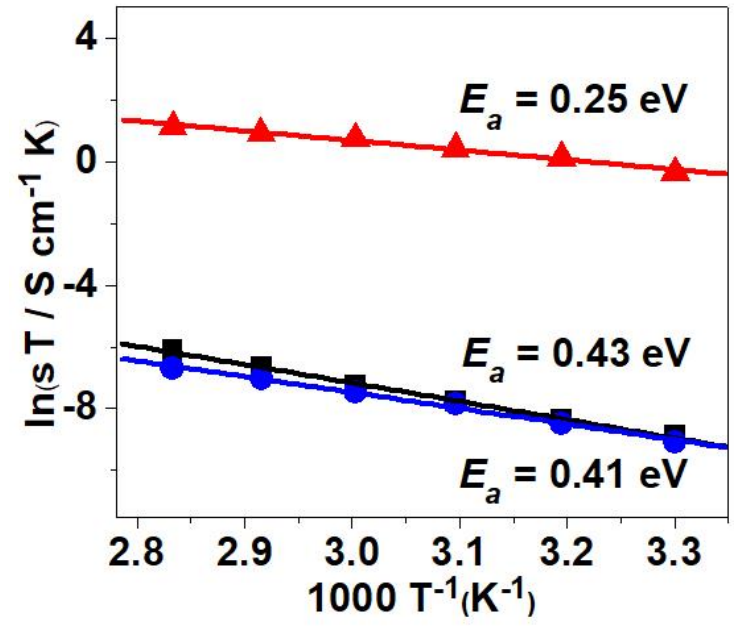

Figure S5. Arrhenius plots for $\mathrm{UiO}-66-\mathrm{SO}_{3} \mathrm{H}$ (red); UiO-66 (black) and $\mathrm{UiO}-66-\mathrm{NH}_{2}$ (blue).

\section{References}

(S1) Li, P.-Z.; Wang, X.-J.; Tan, R. H. D.; Zhang, Q.; Zou, R.; Zhao, Y. Rationally "clicked" post-modification of a highly stable metal-organic framework and its high improvement on $\mathrm{CO}_{2}$-selective capture. $R S C A d v . \mathbf{2 0 1 3}, 3,15566-15570$.

(S2) Goto, Y.; Sato, H.; Shinkai, S.; Sada, K. "Clickable” Metal-Organic Framework. J. Am. Chem. Soc. 2008, 130, 14354-14355. 